\title{
Microstructure and Mechanical Properties of Magnesium Matrix Composites Interpenetrated by Different Reinforcement
}

\author{
Shuxu Wu ${ }^{1}$, Shouren Wang ${ }^{1, *}$, Daosheng Wen ${ }^{1}$, Gaoqi Wang ${ }^{1}$ and Yong Wang ${ }^{2}$ \\ 1 School of Mechanical Engineering, University of Jinan, Jinan 250022, China; Shuxu1994@gmail.com (S.W.); \\ me_wends@ujn.edu.cn (D.W.); me_wanggq@ujn.edu.cn (G.W.) \\ 2 School of Physics and Technology, University of Jinan, Jinan 250022, China; ss_wangy@ujn.edu.cn \\ * Correspondence: me_wangsr@ujn.edu.cn
}

Received: 15 September 2018; Accepted: 19 October 2018; Published: 23 October 2018

\begin{abstract}
The present work discusses the microstructure and mechanical properties of the as-cast and as-extruded metal matrix composites interpenetrated by stainless steel (Fe-18Cr-9Ni), titanium alloy (Ti-6Al-4V), and aluminum alloy (Al-5Mg-3Zn) three-dimensional network reinforcement materials. The results show that the different reinforcement materials have different degrees of improvement on the microstructures and mechanical properties of the magnesium matrix composites. Among them, magnesium matrix composites interpenetrated by stainless steel reinforcement have maximum tensile strength, yield strength, and elongation, which are $355 \mathrm{MPa}, 241 \mathrm{MPa}$, and $13 \%$, respectively. Compared with the matrix, it increases by $47.9 \%, 60.7 \%$ and $85.7 \%$, respectively. Moreover, compared with the as-cast state, the as-extruded sample has a relatively small grain size and a uniform size distribution. The grain size of the as-cast magnesium matrix composites is mainly concentrated at $200-300 \mu \mathrm{m}$, whereas the extruded state is mainly concentrated at 10-30 $\mu \mathrm{m}$. The reason is that the coordination deformation of reinforcement and matrix, and the occurrence of dynamic recrystallization, cause grain refinement of magnesium matrix composite during the extrusion process, thereby improving its mechanical properties. Moreover, the improvement is attributed to the effect of the reinforcement itself, and the degree of grain refinement of the metal matrix composites.
\end{abstract}

Keywords: microstructure; mechanical properties; interpenetrating composites; magnesium alloy; metal reinforcement; metal matrix composites

\section{Introduction}

The metal matrix composites (MMCs) are a new type of structural material which is compounded by metal and alloy, as a matrix, through a certain process. The composite material has outstanding advantages, such as high specific modulus and specific strength, which is widely used in the fields of aviation, aerospace, and military protection [1,2]. In the area of the matrix, most metallic systems have been explored for use in metal matrix composites, including $\mathrm{Al}, \mathrm{Be}, \mathrm{Ti}, \mathrm{Mg}, \mathrm{Fe}, \mathrm{Ni}, \mathrm{Co}$, and $\mathrm{Ag}$, and, by far, the most mature technology is the preparation of aluminum matrix composites [3]. However, the traditional composite materials are usually reinforced by particles, fibers, and whiskers [4-6]. In recent years, with the requirement of the "structure-function" integration of composite materials and the development trend of increasing the volume fraction of the second phase particles, a new type of composite material has emerged, namely, the network interpenetrating structure of the reinforced the composite material. There is a new reinforcement method in which MMCs penetrate each other through three-dimensional network reinforcements, which have the mechanical characteristics of continuous enhancement, and the microstructure characteristics of intertwisting and interpenetrating with the 
matrix [7-9]. Since the matrix and reinforcement form a three-dimensional network structure in which the respective continuous and interpenetrating structures are formed in the space, the characteristics of each component constituting the network structure remain substantially unchanged, so its comprehensive reinforcement effect is generally better than the traditional reinforcement method, which makes it possible to obtain high-performance, multi-functional composite materials [10,11]. However, up to now, the metal matrix has been almost reinforced by ceramic, carbon nanotubes, or another brittle three-dimensional network reinforcement [12-14]. Due to the low toughness and shock resistance of brittle materials, these interpenetrating composites cannot undergo more machining deformation [15]. Particularly, in the case of fabricating structures having irregular cross-sectional shapes, their applications will be limited.

In order to solve the above problems, the further development direction of the network interpenetrating metal matrix composites may be on the choice of the reinforcement materials, which can not only improve the strength of the composites, but also improve the plasticity [16]. Therefore, when metal is selected as a reinforcement for the composites, the metal matrix composites interpenetrated by metal reinforcement (MIMC) will have good forgeability and workability, which can be processed and deformed by multiple machining processes, such as torsion straining (TS), warm rolling (WR), twin-roll casting (TRC), and reciprocal extrusion (RE), etc. [17-19]. Among them, the extrusion process of the metal matrix composites can significantly improve the combined quality between matrix and reinforcement [20,21]. However, few researchers have studied the microstructure and mechanical properties of MIMC, especially magnesium matrix composites [22,23]. At the same time, magnesium and its alloy have the advantages of being lightweight, and having good casting performance, good damping, and shock absorbability, but their mechanical strength is poor [24,25]. Therefore, this article proposes a network interpenetrating bimetallic magnesium matrix composite using three metal-made network skeletons as reinforcements. This bimetallic magnesium matrix composite can not only make up for the deficiency of magnesium alloy in terms of strength and hardness, but also has a better toughness and absorbing properties as a metal material than ceramic materials.

Therefore, the current work is mainly to manufacture the magnesium matrix composites interpenetrated by steel reinforcement, titanium reinforcement, and aluminum reinforcement and the subsequent extrusion process and, then, study the effects of different three-dimensional network reinforcement on the mechanical properties and microstructure of the magnesium matrix composites.

\section{Materials and Methods}

\subsection{MIMC Composites Fabrication}

Previously, our team used a three-dimensional network of $\mathrm{Si}_{3} \mathrm{~N}_{4}$ ceramic structure and pressure-assisted and vacuum-driven permeation technique to reinforce magnesium matrix composites $\left(\mathrm{Si}_{3} \mathrm{~N}_{4}-\mathrm{Mg}\right)$ [26]. The preparation process was as follows: a porous ceramic skeleton was prepared from high-purity $\beta-\mathrm{Si}_{3} \mathrm{~N}_{4}$ powder $\left(97 \%\right.$ of $\mathrm{Si}_{3} \mathrm{~N}_{4}$ and less than $100 \mu \mathrm{m}$ in diameter, Shanghai Silicon Materials Plant, Shanghai, China). The porous reticulated polyurethane (PU) was selected as the original framework, and the porous prefabricated parts were prepared through the replication process. Figure 1a shows the porous network of $\mathrm{Si}_{3} \mathrm{~N}_{4}$ ceramic skeleton after impregnation and sintering. Then, it was heated in a nitrogen-filled muffle furnace (SQFL-1700, Shanghai, China) until it reached the desired processing temperature of $750{ }^{\circ} \mathrm{C}$, at which time, the liquid magnesium alloy was infiltrated into the preform skeleton by means of pressure-assisted and vacuum-driven permeation techniques. Figure $1 \mathrm{~b}$ shows a $\mathrm{Si}_{3} \mathrm{~N}_{4}-\mathrm{Mg}$ metal matrix composite, in which zone "1" is the $\mathrm{Si}_{3} \mathrm{~N}_{4}$ three-dimensional network skeleton, and zone " 2 " is the Mg matrix. Figure 1c shows the schematic diagram of the infiltration device, and the mechanical properties of $\mathrm{Si}_{3} \mathrm{~N}_{4}-\mathrm{Mg}$ matrix composite are shown in Table 1 , which indicates that the ceramic network reinforcement significantly enhances the elastic modulus, rockwell hardness, and tensile strength of the matrix, while the elongation is decreased $[27,28]$. 

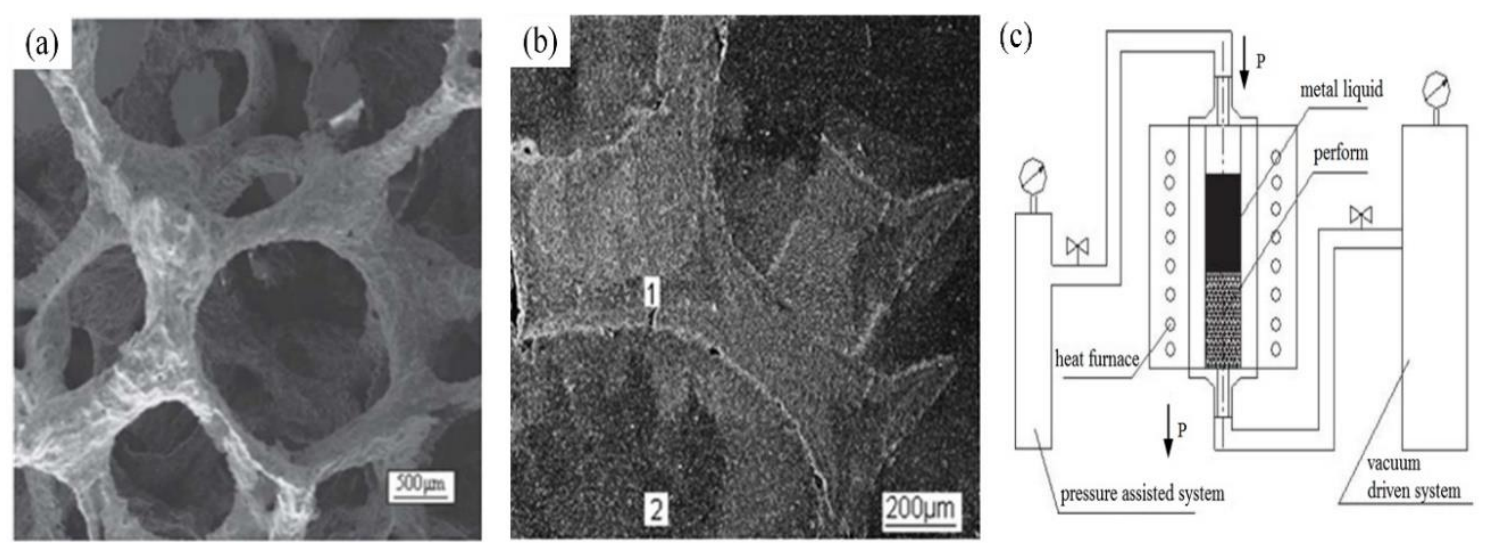

Figure 1. SEM micrographs image and technical diagram: (a) $\mathrm{Si}_{3} \mathrm{~N}_{4}$ reticulated ceramic skeleton; (b) $\mathrm{Si}_{3} \mathrm{~N}_{4}-\mathrm{Mg}$ composite; (c) the schematic diagram of infiltration equipment.

Table 1. The mechanical properties of $\mathrm{Mg}$ alloy and $\mathrm{Si}_{3} \mathrm{~N}_{4}-\mathrm{Mg}$ composite.

\begin{tabular}{ccccc}
\hline Materials & $\begin{array}{c}\text { Elastic Module } \\
\text { (GPa) }\end{array}$ & $\begin{array}{c}\text { Rockwell Hardness } \\
\text { (HRB) }\end{array}$ & $\begin{array}{c}\text { Elongation } \\
\text { (\%) }\end{array}$ & $\begin{array}{c}\text { Tensile Strength } \\
\text { (MPa) }\end{array}$ \\
\hline $\mathrm{Mg}$ alloy & 70 & 65 & 9.5 & 330 \\
$12 \mathrm{Si}_{3} \mathrm{~N}_{4}-\mathrm{Mg}$ & 110 & 71 & 3.2 & 345 \\
$25 \mathrm{Si}_{3} \mathrm{~N}_{4}-\mathrm{Mg}$ & 133 & 78 & 1.6 & 340 \\
\hline
\end{tabular}

Recently, however, our team tried a new and simple process to fabricate the magnesium matrix composites. The network skeleton of the reinforcement designed by three-dimensional weaving technology was shown in Figure 2a, and the model of the metal matrix composite of the infiltrated reinforcement was shown in Figure $2 b$. The reinforcement skeleton materials were chosen as stainless steel (Fe-18Cr-9Ni), titanium alloy (Ti-6Al-4V), and aluminum alloy (Al-5Mg-3Zn), respectively, while magnesium matrix was selected as AZ31(Mg-3.31Al-1.05Zn). The skeleton was fabricated using the three-dimensional weaving techniques, and measured by Archimedes measurements (ASTM C373), with a reinforcement volume fraction of approximately $15 \%$. Unlike the preparation of $\mathrm{Si}_{3} \mathrm{~N}_{4}-\mathrm{Mg}$ matrix composites, the MIMC composites' fabrication processing was applied pressure infiltration technology, which is shown in Figure 2c. The entire experiment was carried out under an inert gas argon atmosphere. Firstly, in the inert atmosphere of a mixture of $\mathrm{CO}_{2}$ and $\mathrm{SF}_{6}$, the furnace temperature was set to $720^{\circ} \mathrm{C}$ to melt the AZ31 alloy. Then, the molten magnesium alloy liquid was poured into an infiltration mold having a temperature of $650{ }^{\circ} \mathrm{C}$ and, finally, the pressure head started to be pressed. At last, the magnesium matrix composites interpenetrated by stainless steel reinforcement (MISC), the magnesium matrix composites interpenetrated by titanium alloy reinforcement (MITC), and the magnesium matrix composites interpenetrated by aluminum alloy reinforcement (MIAC), were fabricated successfully.

\subsection{The Extrusion Process}

The diameter of the extruded blank was machined to $59 \mathrm{~mm}$ prior to extrusion of the metal matrix composite. Under the temperature of $300{ }^{\circ} \mathrm{C}$, the billet was extruded at a speed of $2 \mathrm{~mm} / \mathrm{s}$ with an extrusion ratio of 30, and a half-angle of the extrusion die of $30^{\circ}$, as shown as in Figure $3 a$. The geometric model of extrusion die was shown in Figure $3 \mathrm{~b}$. The extruded material was immediately quenched to prevent the grain from growing. 
(a)

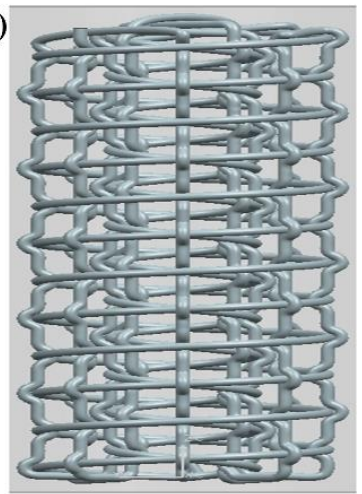

(b)

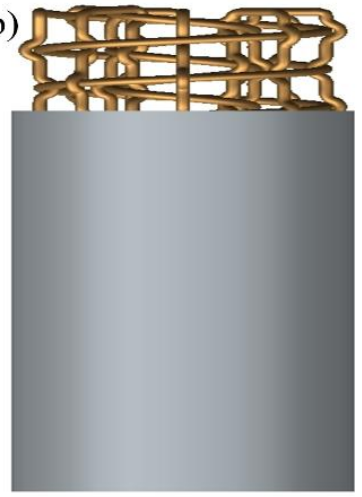

(c)

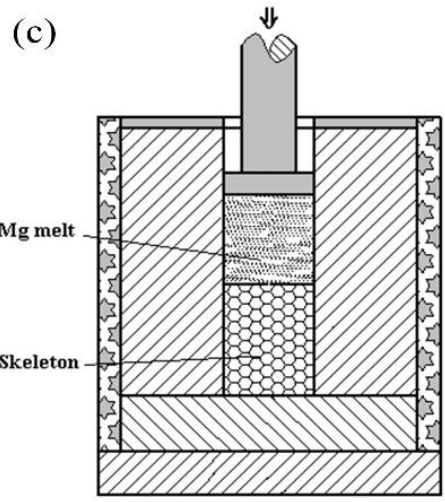

(a) reinforcement; (b) MIMC

Figure 2. Three-dimensional model image and t
composites; (c) the pressure infiltration technology.
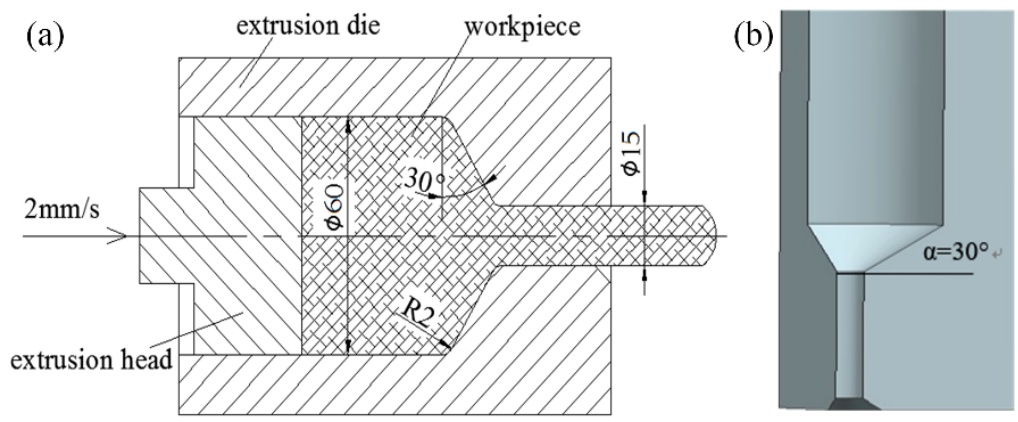

Figure 3. The schematic diagram of extrusion process: (a) pressure infiltration processing of the extrusion process; (b) 1/4 extrusion die of matrix composites interpenetrated by metal reinforcement (MIMC) composites.

\subsection{Microstructure Characterization}

The samples were mechanically polished using a polycrystalline diamond suspension ethylene glycol organic solution for observation of the optical microstructure (OM, Keyence VW-5000, Osaka, Japan). Then, the samples were subjected to etching in a solution consisting of acetic acid $(5 \mathrm{~mL})$, picric acid $(5 \mathrm{~g})$, ethanol $(100 \mathrm{~mL})$, and distilled water $(10 \mathrm{~mL})$, for $7 \mathrm{~s}$, to reveal the crystal structure. The average grain size was analyzed by the Image Pro Plus (IPP, Media Cybernetics, Rockville, MD, USA). In addition, the EBSD samples were prepared by mechanical polishing using 2000\# sandpaper and, then, by electric polishing in an electrolyte consisting of $400 \mathrm{~mL}$ butyl glycol $\left(\mathrm{C}_{4} \mathrm{H}_{10} \mathrm{O}_{2}, 99.5 \%\right)$, $80 \mathrm{~mL}$ ethanol $\left(\mathrm{C}_{2} \mathrm{H}_{6} \mathrm{O}, 95 \%\right)$, and $40 \mathrm{~mL}$ perchloric acid $\left(\mathrm{HClO}_{4}, 70 \%\right)$, at a voltage of $11 \mathrm{~V}$ for $120 \mathrm{~s}$. Microstructure and morphology of MIMC composites were investigated by scanning electron microscopy (SEM, Hitachi S-4800, Tokyo, Japan), and the elemental composition of the samples was determined by the energy dispersive spectroscopy (EDS, Oxford Instruments Inca Energy 350, Oxford, $\mathrm{UK})$, as well as grain distribution and diameter measurements, which were determined using electron backscatter diffraction (EBSD, Oxford Instruments NordlysMax2, Oxford, UK).

\subsection{Mechanical Properties Test}

The extruded samples used for tensile testing were processed on a CNC lathe (CJK6130L, Shanghai, China), in accordance to the procedure outlined in American Society for Testing and Materials (ASTM E8M-96). There were no obvious processing marks on the surface of the test piece, nor were there any signs of breaking nucleation. The mechanical properties of the samples were tested using an Instron 5569 testing machine (Instron, Shanghai, China) with a crosshead moving speed of $0.1 \mathrm{~mm} / \mathrm{min}$, and the strain was monitored by a strain gage of $20 \mathrm{~mm}$ in length. At the same time, the test 
comparisons of the AZ31 magnesium alloy were carried out, and each tensile value was the average of at least three measurements.

\section{Results}

\subsection{Microstructure}

Figure 4 shows the surface microstructure and cross-section characteristics of MIMC composites. From Figure $4 \mathrm{a}$, the matrix and reinforcement are interpenetrating, anisotropic, and interwoven. In addition, in the longitudinal direction, a portion of the structure of the interpenetrating network of reinforcements is exposed from the matrix (white circles), and another portion of the reinforcement is wrapped and buried by magnesium matrix. Only a few are exposed from the matrix in the transverse direction (black arrow). In addition, the matrix and reinforcement form a good interface combination, as shown as in Figure $4 \mathrm{~b}$. Furthermore, the distribution of the chemical elements of the samples are examined by EDS, and subjected to line scanning, as shown as in Figure 5. The reinforcements of the circular area are stainless steel (cyan line in Figure 5a), titanium alloy (blue line in Figure 5b), and aluminum alloy (cyan line in Figure 5c), respectively. The magnesium matrix is represented as a red line in the MISC and MIAC composites, however, it is described as a green line in MITC composite.
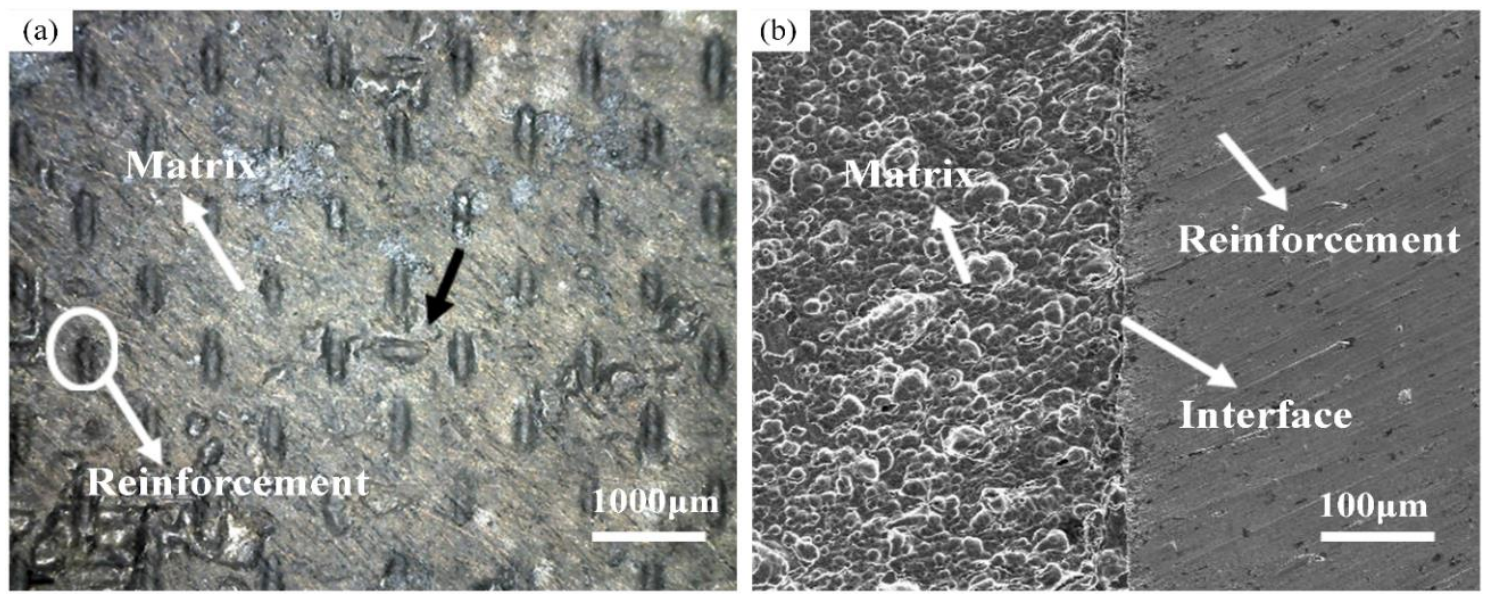

Figure 4. SEM micrograph of MIMC composites: (a) the surface microstructure; (b) cross-section of reinforcement with matrix.
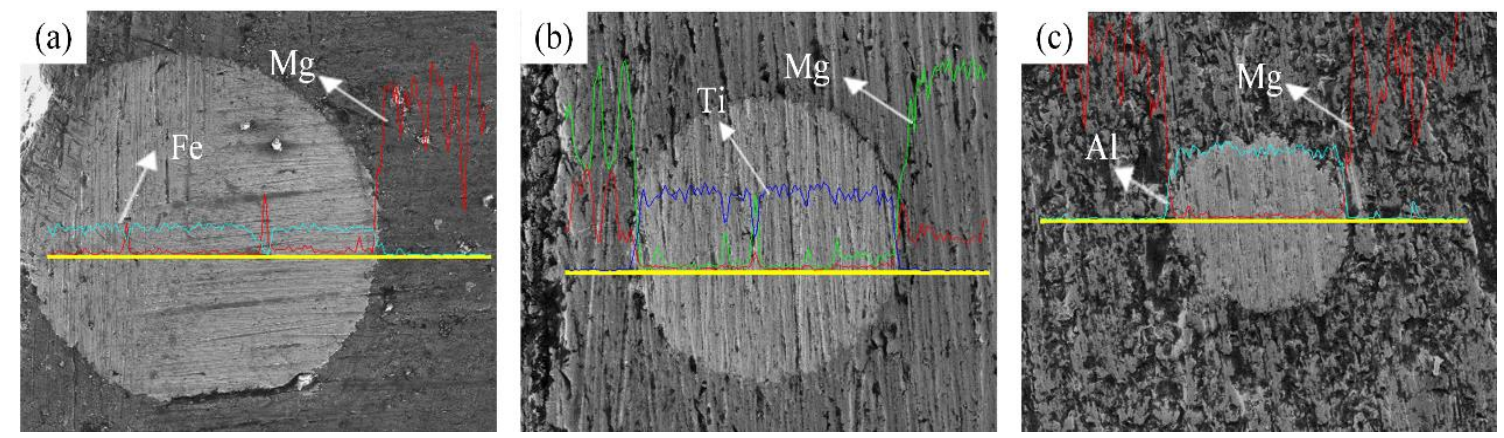

Figure 5. The energy dispersive spectroscopy (EDS) analysis of MIMC composites: (a) magnesium matrix composites interpenetrated by stainless steel reinforcement (MISC); (b) magnesium matrix composites interpenetrated by titanium alloy reinforcement (MITC); (c) magnesium matrix composites interpenetrated by aluminum alloy reinforcement (MIAC).

Figure 6 shows the OM microstructure morphology and grain size distribution of magnesium matrix in three kinds of composite as-cast states. In MIMC composites, their grain distribution and grain size have the same characteristics, that is, the grain distribution does not obey a normal 
distribution and is randomly distributed. In addition, the grain size is mainly concentrated in the range 200-300 $\mu \mathrm{m}$. Therefore, the results show that the grain and its area fraction are not affected by any of the reinforcement materials. However, compared with the as-cast state (Figure $6 \mathrm{a}, \mathrm{c}, \mathrm{e}$ ), the micromorphology of the as-extruded samples has greater changes, which are shown in Figure 7a,c,e. The relatively small grain size of the as-extruded samples is owing to the accumulation of shear strain and dynamic recrystallization during extrusion. However, the grain refinement degree is different in three kinds of composites. In MISC composites, it can be seen, from Figure $7 \mathrm{a}$, that the grain size follows a normal distribution. Moreover, most of the grain size is $10-20 \mu \mathrm{m}$, so the average grain size is $14 \mu \mathrm{m}$. In MITC composites, although the grain size does not conform to the normal distribution (Figure 7d), most of them are concentrated between 15-30 $\mu \mathrm{m}$. Therefore, the average grain size is $20 \mu \mathrm{m}$. In MIAC composites, the grain size adheres to the Weibull distribution (Figure 7f), and most of them are concentrated between $20-30 \mu \mathrm{m}$. The average grain size is $24 \mu \mathrm{m}$. In short, the different reinforcement materials result in different microstructure characterization of magnesium matrix during deformation. The reason is that, due to the different strengths of reinforcement, the magnesium matrix bears a different stress from the reinforcement during extrusion. As we know, magnesium matrix alloys usually form a strong texture, resulting in the decreases of ductility at room temperature because of their intrinsic characterization of the hexagonal close-packed structure [29]. Since the room temperature-forming properties of the magnesium alloys are mainly affected by the initial crystal structure of the basal plane, the improvement of the crystal grains will significantly improve the formability of the MIMC composites [30]. In MISC composites, the three-dimensional network of stainless-steel has the highest strength, which leads to greater stress on magnesium grains, thus causing a till of the basal plane during coordinated deformation, and a minimum average grain size. Therefore, the dynamic recrystallization occurs in the vicinity of the reinforcement of magnesium matrix composite. Furthermore, the difference between size distribution and grain refinement can be explained by the changes in the grain orientation of magnesium matrix composite by EBSD test. Figure 8a shows that the grain orientation of the as-cast magnesium matrix composite (MIMC) is almost randomly distributed. Figure $8 \mathbf{b}-\mathrm{d}$ reveal the grain orientation changes of the as-extruded magnesium matrix composite. From Figure 8b (MISC), the results show that during the extrusion, the grain orientation forms a strong peak at the center of the basal pole figure of $\{0001\}$. However, in the MIAC composites, $\{0001\}$ basal pole figure exhibits a divergence state, due to a relatively small stress for the aluminum alloy imposed to magnesium matrix, as shown as in Figure 8d. From Figure 8c (MITC), it is shown that the grain orientation is between MISC and MIAC.

\subsection{Mechanical Properties}

The MIMC composites exhibit different mechanical properties because of the difference of reinforcement materials. Figure 9 shows the mechanical properties change with different reinforcement materials. Compared with AZ31 magnesium alloy, the MIMC composites have a significant improvement in the yield strength (YS), ultimate tensile strength (UTS), and elongation (E). The improvement in mechanical performance is attributed to the following as (1) superior mechanical properties of the reinforcement itself; (2) the reinforcements have a good interface with the matrix; (3) effective load transfer can be carried out from matrix to reinforcement; and (4) fine and evenly distributed grain are produced during coordination deformation of the reinforcement and matrix. 

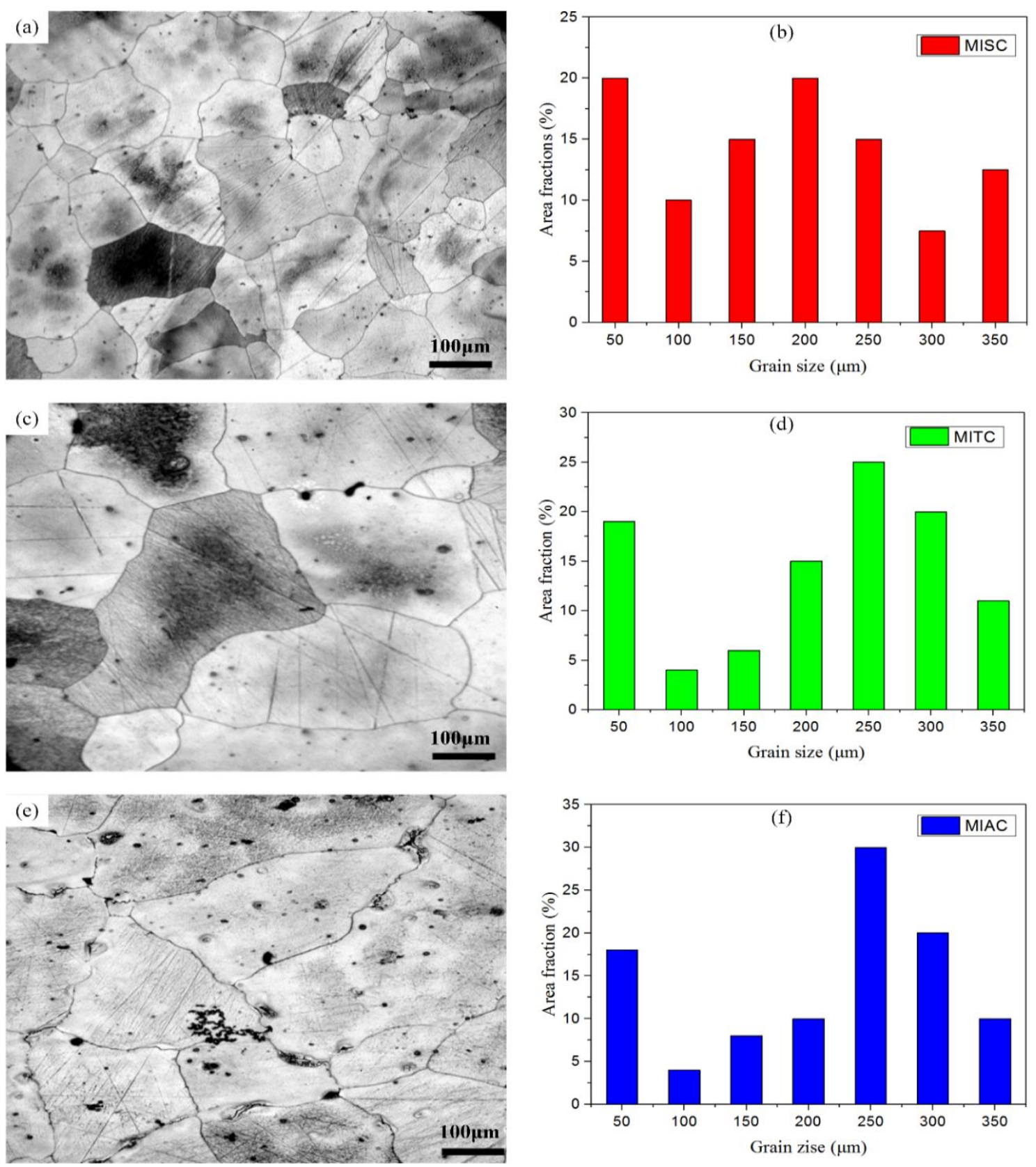

Figure 6. The optical microstructure and the grain size distributions of magnesium matrix composite in three kinds of reinforcement as-cast states: $(\mathbf{a}, \mathbf{b})$ MISC; $(\mathbf{c}, \mathbf{d})$ MITC; $(\mathbf{e}, \mathbf{f})$ MIAC. 

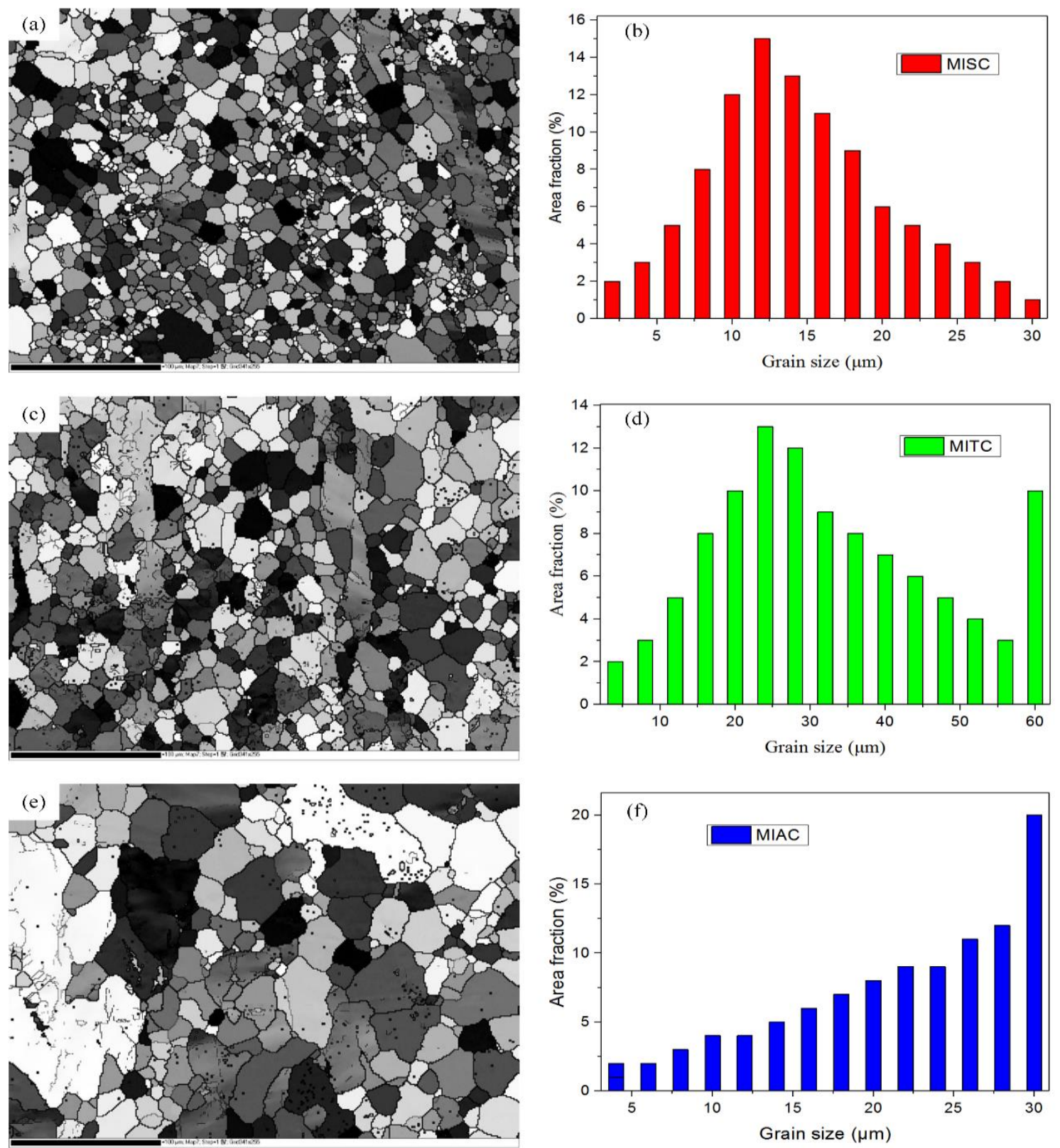

Figure 7. The SEM and the grain size distributions of magnesium matrix composite in three kinds of reinforcement as-extruded states: (a,b) MISC; (c,d) MITC; (e,f) MIAC.
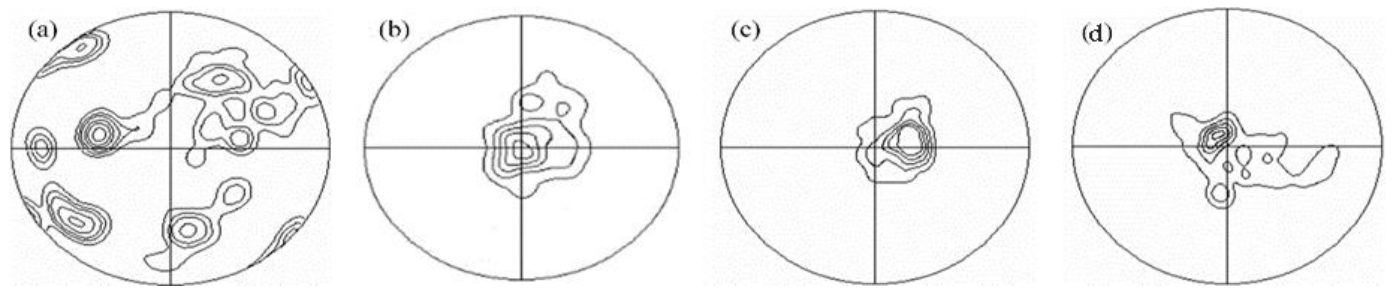

Figure 8. The $\{0001\}$ basal pole figures: (a) cast states of MIMC; (b) extruded state of MISC; (c) extruded state of MITC; (d) extruded state of MIAC. 

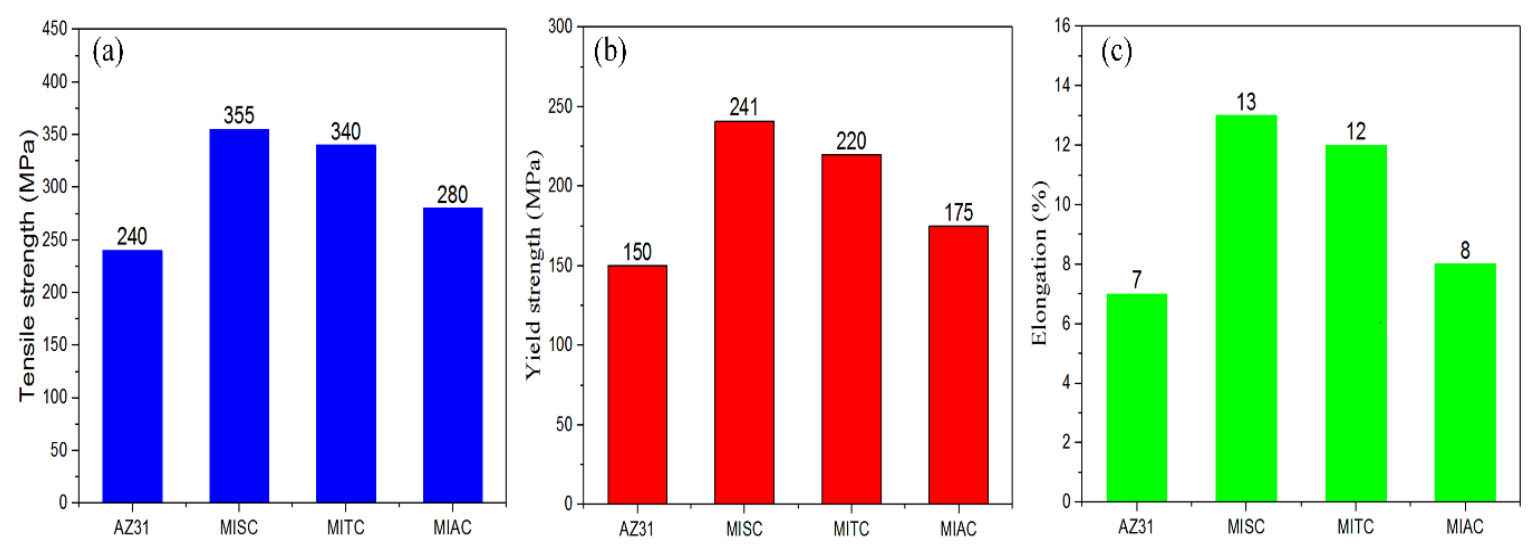

Figure 9. The mechanical properties of AZ31, MISC, MITC, and MIAC: (a) UTS; (b) YS; (c) E.

Among the three kinds of composites, the MISC composites have the maximum values of UTS (Figure 9a), YS (Figure 9b), and E (Figure 9c), which are $355 \mathrm{MPa}, 241 \mathrm{MPa}$, and 13\%. For each parameter, comparing with the AZ31, the increase is $47.9 \%, 60.7 \%$, and $85.7 \%$, respectively, while the MITC composites followed, the mechanical properties are $340 \mathrm{MPa}, 220 \mathrm{MPa}$, and $12 \%$, increasing by $41.7 \%, 46.7 \%$, and $71.4 \%$, respectively. The MIAC composites are the minimum, the mechanical properties of which are $280 \mathrm{MPa}, 175 \mathrm{MPa}$, and $8 \%$, increasing by $16.7 \%, 16.7 \%$, and $14.3 \%$, respectively. These changes are ascribed to two factors. One is the influence of reinforcement itself, and the mechanical properties of the three network reinforcements are shown in Table 2. Another is the influence of the grain refinement degree of matrix alloy.

Table 2. The mechanical properties of the three network reinforcements.

\begin{tabular}{cccc}
\hline Materials & $\begin{array}{c}\text { Tensile Strength } \\
\mathbf{( M P a )}\end{array}$ & $\begin{array}{c}\text { Yield Strength } \\
\mathbf{( M P a )}\end{array}$ & $\begin{array}{c}\text { Elongation } \\
\mathbf{( \% )}\end{array}$ \\
\hline $\mathrm{Fe}-18 \mathrm{Cr}-9 \mathrm{Ni}$ & 893 & 824 & 36 \\
$\mathrm{Ti}-6 \mathrm{Al}-4 \mathrm{~V}$ & 790 & 710 & 21 \\
$\mathrm{Al}-5 \mathrm{Mg}-3 \mathrm{Zn}$ & 542 & 520 & 11 \\
\hline
\end{tabular}

\section{Discussions}

The reinforcement and matrix of MIMC composites are regarded as two interpenetrating pore structures or network structures, which are shown in Figure 10a. Owing to that one kind of metal phase is interpenetrated by another metal phase, the mechanical models of the network structure of MIMC composites does not follow the brittle fracture mode which is shown in Figure 10b, it follows the elastic plastic mode which is shown in Figure 10c, and this deformation mode is the main failure mode of MIMC composites [31,32]. Considering the linear elastic elements, the elastic modulus of interpenetrating composites is estimated as Equation (1), according to the mixing rule

$$
E_{C}=E_{M} V_{M}+E_{R} V_{R}
$$

where $E_{C}, E_{M}$, and $E_{R}$ are, respectively, the elastic modulus of composites (C), matrix $(\mathrm{M})$, and reinforcement (R), and $V_{M}$ and $V_{R}$ are, respectively, the volume fraction of matrix and reinforcement. 
(a)

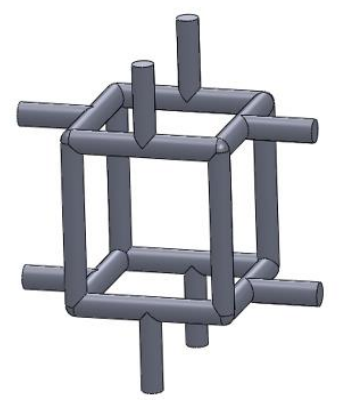

(b)

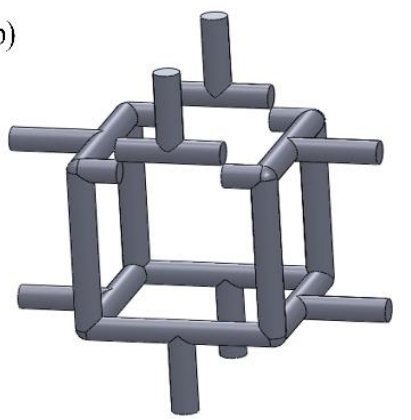

(c)

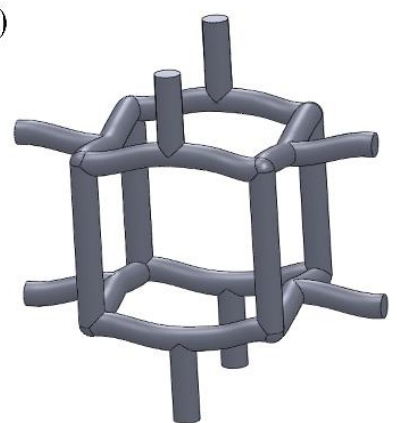

Figure 10. The mechanical model of network structure: (a) the unit model; (b) the brittle model; (c) the elastic plastic model.

Considering the elastic modulus influence, the constitutive mechanical mode of MIMC is proposed according to mixture law of composites, as shown in Equations (2) and (3).

$$
\begin{gathered}
\text { Upper limit model : } E_{C} X_{C}=\sum_{i=1}^{n} E_{i} X_{i} V_{i}, \\
\text { Lower limit model : } \frac{E_{C}}{X_{C}}=\sum_{i=1}^{n} \frac{E_{i} V_{i}}{X_{i}},
\end{gathered}
$$

where $X_{C}$ represents the mechanical properties of composite materials, and $X_{i}$ and $V_{i}$ represent the mechanical properties and volume fractions of different composite phase, respectively. For two phases interpenetrating composites, the mechanical properties, such as tensile strength, yield strength, and elongation, are rewritten as Equations (4)-(7), according to the above equations,

$$
\begin{gathered}
E_{C} \sigma_{C}=E_{M} V_{M} \sigma_{M}+E_{R} V_{R} \sigma_{R}, \\
\frac{E_{C}}{\sigma_{C}}=E_{M} \frac{V_{M}}{\sigma_{M}}+E_{R} \frac{V_{R}}{\sigma_{R}}, \\
E_{C} \delta_{C}=E_{M} V_{M} \delta_{M}+E_{R} V_{R} \delta_{R}, \\
\frac{E_{C}}{\delta_{C}}=E_{M} \frac{V_{M}}{\delta_{M}}+E_{R} \frac{V_{R}}{\delta_{R}},
\end{gathered}
$$

where $\sigma$ and $V$ represent, respectively, the tensile strength or yield strength and volume fractions of the matrix $(\mathrm{M})$ and reinforcement $(\mathrm{R})$, and $\delta$ represents the elongation of the matrix $(\mathrm{M})$ and reinforcement $(\mathrm{R})$.

Combining Equation (1) to Equations (4)-(7), the following Equations (8)-(11) are obtained:

$$
\begin{gathered}
\text { Upper limit model : } \sigma_{C}=\frac{E_{M}}{E_{M} V_{M}+E_{R} V_{R}} V_{M} \sigma_{M}+\frac{E_{R}}{E_{M} V_{M}+E_{R} V_{R}} V_{R} \sigma_{R}, \\
\text { Lower limit model : } \frac{1}{\sigma_{C}}=\frac{E_{M}}{E_{M} V_{M}+E_{R} V_{R}} \frac{V_{M}}{\sigma_{M}}+\frac{E_{R}}{E_{M} V_{M}+E_{R} V_{R}} \frac{V_{R}}{\sigma_{R}}, \\
\text { Upper limit model : } \delta_{C}=\frac{E_{M}}{E_{M} V_{M}+E_{R} V_{R}} V_{M} \delta_{M}+\frac{E_{R}}{E_{M} V_{M}+E_{R} V_{R}} V_{R} \delta_{R}, \\
\text { Lower limit model : } \frac{1}{\delta_{C}}=\frac{E_{M}}{E_{M} V_{M}+E_{R} V_{R}} \frac{V_{M}}{\delta_{M}}+\frac{E_{R}}{E_{M} V_{M}+E_{R} V_{R}} \frac{V_{R}}{\delta_{R}} .
\end{gathered}
$$

According to the above mathematics model, the relationship between volume fraction and tensile strength of magnesium matrix composites interpenetrated by different reinforcement is shown in Figure 11. The results show that as the volume fraction of reinforcement increases, the continuous improving trend of tensile strength is more obvious. Similarly, the yield strength and elongation also 
have the same regularity. Compared with the tested results in Figure 9, the results of the mathematics model are the same. Therefore, it can be considered that the mathematics model of the composite material, derived from this paper, is correct and provides a good theoretical guidance for the test.

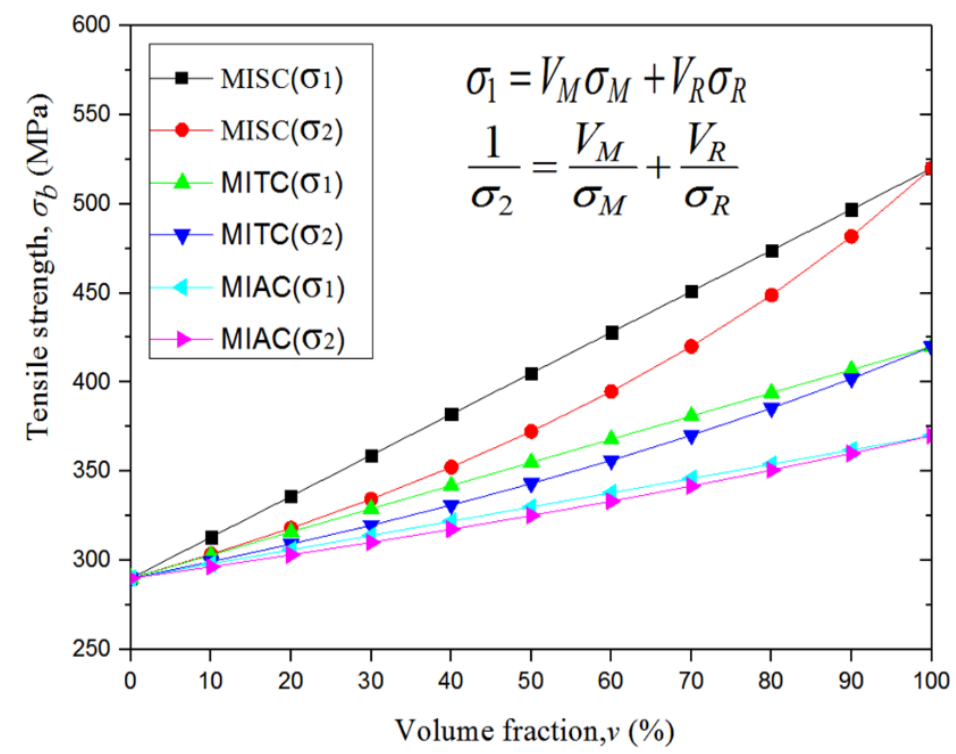

Figure 11. The relationship between tensile strength and volume fraction of magnesium matrix composites interpenetrated by different reinforcement.

\section{Conclusions}

1. The magnesium matrix composites reinforced by stainless steel (Fe-18Cr-9Ni), titanium alloy (Ti-6Al-4V), and aluminum alloy (Al-5Mg-3Zn), were prepared by the pressure infiltration technology. The reinforcements of the composites are interwoven with the matrix and have an integrated interface.

2. The grain size and distribution in the as-cast magnesium matrix composites have the same characteristics, and their sizes are mainly concentrated at $200-300 \mu \mathrm{m}$, and the size distribution is random and does not obey normal distribution. However, during the extrusion process, the grain size of magnesium matrix composite is more refined than that of the as-cast state, because of the dynamic recrystallization and the superposition of shear strain, and its size is mostly concentrated at 10-30 $\mu \mathrm{m}$. In addition, the grain size distributions of MISC and MIAC follow the normal distribution and the Wien distribution, respectively.

3. Different reinforcement materials result in different microstructure characterization of magnesium matrix during extrusion. The average grain sizes of magnesium matrix composites with the reinforcements of MISC, MITC, and MIAC are 14, 20, and $24 \mu \mathrm{m}$, respectively.

4. Compared with AZ31, the mechanical properties of metal composites interpenetrated by metal reinforcement have a significant improvement. Different MIMCs with different reinforcements exhibit different mechanical properties. Among the three composite materials, the tensile strength, yield strength, and elongation of MISC are $355 \mathrm{MPa}, 241 \mathrm{MPa}$, and 13\%, with an increase of $47.9 \%$, $60.7 \%$, and $85.7 \%$, respectively; while for MITC, they are $340 \mathrm{MPa}, 220 \mathrm{MPa}$, and $12 \%$, with an increase of $41.7 \%, 46.7 \%$, and $71.4 \%$, respectively; and for MIAC, are $280 \mathrm{MPa}, 175 \mathrm{MPa}$, and $8 \%$, an increase of $16.7 \%, 16.7 \%$, and $14.3 \%$, respectively.

Author Contributions: S.W. (Shouren Wang) wrote the main part of the manuscript and developed the planning of the experiment. S.W. (Shuxu Wu) and Y.W. carried out the preparation of different composite materials and tested the mechanical properties. D.W. and G.W. performed characterization of the microstructure of the samples. S.W. (Shouren Wang) summed up the article and conducted a final review. S.W. (Shuxu Wu) made the final typesetting of the article. 
Funding: This research was funded by the National Natural Science Foundation of China (No. 51872122), Shandong Key Research and Development Plan, China (No.: 2017GGX30140, 2016JMRH0218) Shandong Provincial Natural Science Foundation, China (No.: ZR2017BEE055), Distinguished Middle-Aged and Young Scientist Encourage and Reward Foundation of Shandong Province (No.: ZR2016EMB01) and Taishan Scholar Engineering Special Funding (2016-2020).

Conflicts of Interest: The authors declare no conflict of interest.

\section{Nomenclature}

$\begin{array}{ll}\text { MMCs } & \text { metal matrix composites } \\ \text { MIMC } & \text { metal matrix composites interpenetrated by metal reinforcement } \\ \text { MISC } & \text { magnesium matrix composites interpenetrated by stainless steel reinforcement } \\ \text { MITC } & \text { magnesium matrix composites interpenetrated by titanium alloy reinforcement } \\ \text { MIAC } & \text { magnesium matrix composites interpenetrated by aluminum alloy reinforcement } \\ \text { WR } & \text { warm rolling } \\ \text { TS } & \text { torsion straining } \\ \text { TRC } & \text { twin-roll casting } \\ \text { RE } & \text { reciprocal extrusion } \\ \text { OM } & \text { optical microstructure } \\ \text { SEM } & \text { scanning electron microscopy } \\ \text { EDS } & \text { energy dispersive spectroscopy } \\ \text { EBSD } & \text { electron backscatter diffraction } \\ \text { CNC } & \text { computer numerical control } \\ \text { YS } & \text { yield strength } \\ \text { UTS } & \text { ultimate tensile strength } \\ \text { E } & \text { elongation } \\ E_{C}, E_{M} \text { and } E_{R} & \text { the elastic modulus of composites, matrix, and reinforcement } \\ V_{M} \text { and } V_{R} & \text { the volume fraction of matrix and reinforcement } \\ X_{C} & \text { the mechanical properties of composite materials } \\ X_{i} \text { and } V_{i} & \text { the mechanical properties and volume fractions of different composite phase } \\ \sigma \text { and } V & \text { the tensile strength or yield strength and volume fractions of the matrix and reinforcement } \\ \delta & \text { the elongation of the matrix and reinforcement } \\ & \end{array}$

\section{References}

1. Mortensen, A.; Llorca, J. Metal matrix composites. Annu. Rev. Mater. Res. 2010, 40, 243-270. [CrossRef]

2. Nicholls, C.J.; Boswell, B.; Davies, I.J.; Islam, M.N. Review of machining metal matrix composites. Int. J. Adv. Manuf. Technol. 2017, 90, 2429-2441. [CrossRef]

3. Kim, C.S.; Cho, K.; Manjili, M.H.; Nezafati, M. Mechanical performance of particulate-reinforced Al metal-matrix composites (MMCs) and Al metal-matrix nano-composites (MMNCs). J. Mater. Sci. 2017, 52, 13319-13349. [CrossRef]

4. Tevatia, A.; Srivastava, S.K. Modified shear lag theory based fatigue crack growth life prediction model for short-fiber reinforced metal matrix composites. Int. J. Fatigue 2015, 70, 123-129. [CrossRef]

5. Roger, J.; Gardiola, B.; Andrieux, J.; Viala, J.C.; Dezellus, O. Synthesis of Ti matrix composites reinforced with TiC particles: Thermodynamic equilibrium and change in microstructure. J. Mater. Sci. 2017, 52, 4129-4141. [CrossRef]

6. Akatsu, T.; Takashima, H.; Shinoda, Y.; Wakai, F.; Wakayama, S. Thermal-shock fracture and damage resistance improved by whisker reinforcement in alumina matrix composite. Int. J. Appl. Ceram. Technol. 2016, 13, 653-661. [CrossRef]

7. Leclerc, W.; Ferguen, N.; Pelegris, C.; Haddad, H.; Bellenger, E.; Guessasma, M. A numerical investigation of effective thermoelastic properties of interconnected alumina/Al composites using FFT and FE approaches. Mech. Mater. 2016, 92, 42-57. [CrossRef]

8. Li, S.; Xiong, D.G.; Liu, M.; Bai, S.X.; Zhao, X. Thermophysical properties of SiC/Al composites with three dimensional interpenetrating network structure. Ceram. Int. 2014, 40, 7539-7544. [CrossRef] 
9. Al-Ketan, O.; Assad, M.A.; Al-Rub, R.K.A. Mechanical properties of periodic interpenetrating phase composites with novel architected microstructures. Compos. Struct. 2017, 176, 9-19. [CrossRef]

10. Cheng, F.F.; Kim, S.M.; Reddy, J.N.; Al-Rub, R.K.A. Modeling of elastoplastic behavior of stainless-steel/bronze interpenetrating phase composites with damage evolution. Int. J. Plasticity 2014, 61, 94-111. [CrossRef]

11. Yao, B.B.; Zhou, Z.Y.; Duan, L.Y.; Chen, Z.T. Anisotropic charpy impact behavior of novel interpenetrating phase composites. Vacuum 2018, 155, 83-90. [CrossRef]

12. Hidalgo-Manrique, P.; Yan, S.; Lin, F.; Hong, Q.; Kinloch, I.A.; Chen, X.; Young, R.J.; Zhang, X.Y.; Dai, S.L. Microstructure and mechanical behaviour of aluminium matrix composites reinforced with graphene oxide and carbon nanotubes. J. Mater. Sci. 2017, 52, 13466-13477. [CrossRef]

13. Boyer, C.; Figueiredo, L.; Pace, R.; Lesoeur, J.; Rouillon, T.; Visage, C.L.; Tassin, J.-F.; Weiss, P.; Guicheux, J.; Rethore, G. Laponite nanoparticle-associated silated hydroxypropylmethyl cellulose as an injectable reinforced interpenetrating network hydrogel for cartilage tissue engineering. Acta Biomater. 2018, 65, 112-122. [CrossRef] [PubMed]

14. Swain, M.V.; Coldea, A.; Bilkhair, A.; Guess, P.C. Interpenetrating network ceramic-resin composite dental restorative materials. Dent. Mater. 2016, 32, 34-42. [CrossRef] [PubMed]

15. Kádár, C.; Máthis, K.; Knapek, M.; Chmelík, F. The effect of matrix composition on the deformation and failure mechanisms in metal matrix syntactic foams during compression. Materials 2017, 10, 196. [CrossRef] [PubMed]

16. Lichtenberg, K.; Weidenmann, K.A. Effect of reinforcement size and orientation on the thermal expansion behavior of metallic glass reinforced metal matrix composites produced by gas pressure infiltration. Thermochim. Acta 2017, 654, 85-92. [CrossRef]

17. Alhajeri, S.N.; Al-Fadhalah, K.J.; Almazrouee, A.I.; Langdon, T.G. Microstructure and microhardness of an Al-6061 metal matrix composite processed by high-pressure torsion. Mater. Charact. 2016, 118, 270-278. [CrossRef]

18. Beranoagirre, A.; Urbikain, G.; Calleja, A.; Lacalle, L.L.D. Hole making by electrical discharge machining (EDM) of $\gamma$-TiAl intermetallic alloys. Metals 2018, 8, 543. [CrossRef]

19. Thompson, A.; Senin, N.; Maskery, I.; Leach, R. Effects of magnification and sampling resolution in X-ray computed tomography for the measurement of additively manufactured metal surfaces. Precis. Eng. 2018, 53, 54-64. [CrossRef]

20. Tokutomi, J.; Uemura, T.; Sugiyama, S.; Shiomi, J.; Yanagimoto, J. Hot extrusion to manufacture the metal matrix composite of carbon nanotube and aluminum with excellent electrical conductivities and mechanical properties. CIRP Ann. 2015, 64, 257-260. [CrossRef]

21. Xin, L.; Yang, W.S.; Zhao, Q.Q.; Dong, R.H.; Liang, X.; Xiu, Z.Y.; Hussain, M.; Wu, G.H. Effect of extrusion treatment on the microstructure and mechanical behavior of $\mathrm{SiC}$ nanowires reinforced $\mathrm{Al}$ matrix composites. Mater. Sci. Eng. A 2017, 682, 38-44. [CrossRef]

22. Srikanth, N.; Kurniawan, L.A.; Gupta, M. Effect of interconnected reinforcement and its content on the damping capacity of aluminium matrix studied by a new circle-fit approach. Compos. Sci. Technol. 2003, 63, 839-849. [CrossRef]

23. Thakur, S.K.; Gupta, M. Use of interconnected reinforcement in magnesium for stiffness critical applications. Mater. Sci. Technol. 2008, 24, 213-220. [CrossRef]

24. Mondet, M.; Barraud, E.; Lemonnier, S.; Guyon, J.; Allain, N.; Grosdidier, T. Microstructure and mechanical properties of AZ91 magnesium alloy developed by spark plasma sintering. Acta Mater. 2016, 119, 55-67. [CrossRef]

25. Ghasali, E.; Alizadeh, M.; Shirvanimoghaddam, K.; Mirzajany, R.; Niazmand, M.; Faeghi-Nia, A.; Ebadzadeh, T. Porous and non-porous alumina reinforced magnesium matrix composite through microwave and spark plasma sintering processes. Mater. Chem. Phys. 2018, 212, 252-259. [CrossRef]

26. Wang, S.R.; Sun, B.; Geng, H.R.; Wang, Y.Z. The abrasive wear properties of $\mathrm{Al}-\mathrm{Mg}-\mathrm{Si}_{3} \mathrm{~N}_{4}$ metal matrix composites. J. Mater. Eng. Perform. 2006, 15, 549-552.

27. Wang, S.R.; Geng, H.R.; Song, B.; Wang, Y.Z. Machinability of metal matrix composites reinforced by 3-D network structure. Appl. Compos. Mater. 2006, 13, 385-395. [CrossRef]

28. Wang, S.R.; Geng, H.R.; Wang, Y.Z. Fabrication and machinability of $\mathrm{Si}_{3} \mathrm{~N}_{4}-\mathrm{Mg}-\mathrm{Al}-\mathrm{Zn}$ (AZ91) composites. Mater. Sci. Technol. 2006, 22, 223-226. [CrossRef] 
29. Arkhurst, B.M.; Lee, M.Y.; Kim, J.H. Effect of resin matrix on the strength of an AZ31 Mg alloy-CFRP joint made by the hot metal pressing technique. Compos. Struct. 2018, 201, 303-314. [CrossRef]

30. Jiang, M.G.; Xu, C.; Yan, H.; Fan, G.H.; Nakata, T.; Lao, C.S.; Chen, R.S.; Kamado, S.; Han, E.H.; Lu, B.H. Unveiling the formation of basal texture variations based on twinning and dynamic recrystallization in AZ31 magnesium alloy during extrusion. Acta Mater. 2018, 157, 53-71. [CrossRef]

31. Mishra, A.; Mahesh, S. A deformation-theory based model of a damaged metal matrix composite. Int. J. Solids Struct. 2017, 121, 228-239. [CrossRef]

32. Trzepieciński, T.; Ryzińska, G.; Gromada, M.; Biglar, M. 3D microstructure-based modelling of the deformation behaviour of ceramic matrix composites. J. Eur. Ceram. Soc. 2018, 38, 2911-2919. [CrossRef]

(C) 2018 by the authors. Licensee MDPI, Basel, Switzerland. This article is an open access article distributed under the terms and conditions of the Creative Commons Attribution (CC BY) license (http://creativecommons.org/licenses/by/4.0/). 